\title{
Synergistically improved thermal conductivity of polyamide- 6 with low melting temperature metal and graphite
}

\author{
Y. C. Jia, H. He ${ }^{*}$, P. Yu, J. Chen, X. L. Lai \\ School of Materials Science and Engineering, South China University of Technology, Wushan Road, Tianhe District, \\ 510640 Guangzhou City, Guangdong Province, China
}

Received 30 December 2015; accepted in revised form 6 March 2016

\begin{abstract}
Low melting temperature metal (LMTM)-tin (Sn) was introduced into polyamide-6 (PA6) and PA6/graphite composites respectively to improve the thermal conductivity of PA6 by melt processing (extruding and injection molding). After introducing $\mathrm{Sn}$, the thermal conductivity of PA6/Sn was nearly constant because of the serious agglomeration of Sn. However, when $20 \mathrm{wt} \%$ (5.4 vol\%) of Sn was added into PA6 containing $50 \mathrm{wt} \%$ (33.3 vol\%) of graphite, the thermal conductivity of the composite was dramatically increased to 5.364 versus $1.852 \mathrm{~W} \cdot(\mathrm{m} \cdot \mathrm{K})^{-1}$ for the PA6/graphite composite, which suggests that the incorporation of graphite and Sn have a significant synergistic effect on the thermal conductivity improvement of PA6. What is more, the electrical conductivity of the composite increased nearly 8 orders of magnitudes after introducing both graphite and Sn. Characterization of microstructure and energy dispersive spectrum analysis (EDS) indicates that the dispersion of $\mathrm{Sn}$ in PA6/graphite/Sn was much more uniform than that of PA6/Sn composite. According to Differential Scanning Calorimetry measurement and EDS, the uniform dispersion of Sn in PA6/graphite/Sn and the high thermal conductivity of PA6/graphite/Sn are speculated to be related with the electron transfer between graphite and Sn, which makes Sn distribute evenly around the graphite layers.
\end{abstract}

Keywords: polymer composites, low melting temperature metal, tin, graphite, thermal conductivity

\section{Introduction}

Low melting temperature metal (LMTM), which have melting temperatures less than $231.9^{\circ} \mathrm{C}$, are frequently used to prepare electrically conducive polymer composites since their high conductivity, liquid state and low viscosity during processing [1-6]. Simultaneously, polymeric materials have attracted increasing interests in the field of thermally conductive materials for the excellent processability, low density and low cost [7]. However, most polymeric materials are thermally insulating and have low thermal conductivities between $0.1-0.5 \mathrm{~W} \cdot(\mathrm{m} \cdot \mathrm{K})^{-1}$ [8]. Traditional thermally conductive materials metal crystals for instance, have a large number of free electrons out- side the nuclei which arrange neatly as shown in Figure 1a. At the heat flow direction, free electrons equipped with thermal energy could move towards low temperature region directly. Most metals have high thermal conductivities for the efficient manner of thermal conduction. Nonmetal crystals arrange neatly as shown in Figure $1 \mathrm{~b}$ and thus the collision of vibrating crystals becomes a major form of thermal conduction. Because of the long-range order of nonmetal crystals, the thermal conductivities of nonmetal crystals are relatively high compared with polymeric materials which have neither free electrons nor perfect arrangement of crystals [9]. Introducing high thermally conductive fillers into polymer matrix is

${ }^{*}$ Corresponding author, e-mail: pshuihe@scut.edu.cn (C) BME-PT 

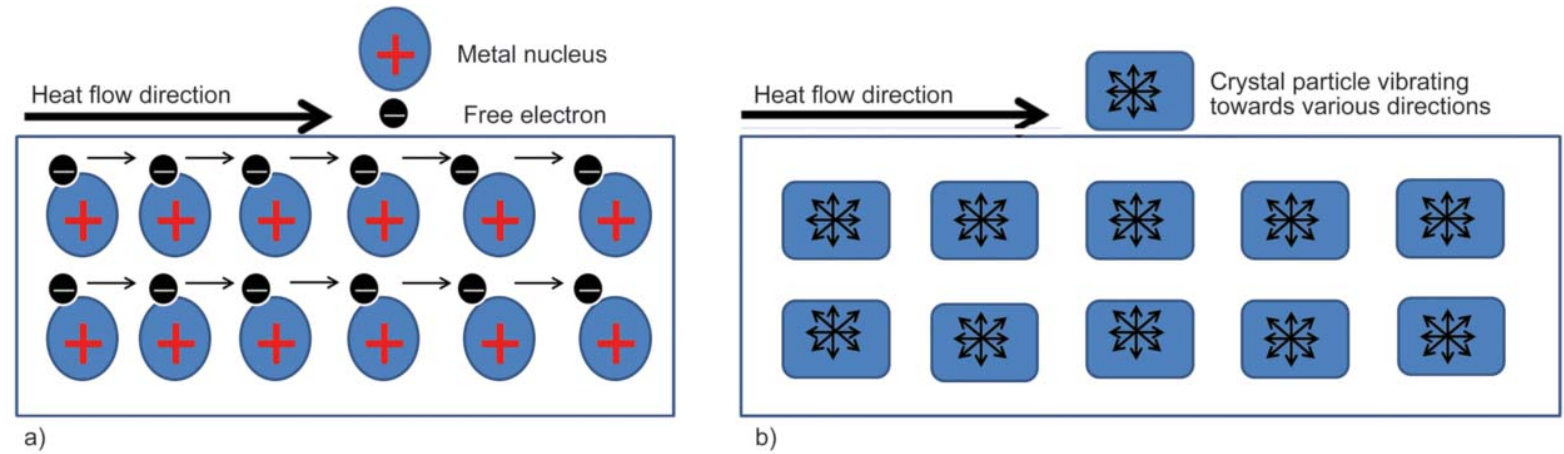

Figure 1. Sketch maps of the structures of (a) metal crystals, and (b) nonmetal crystals

a facile way to increase the thermal conductivities of polymeric materials [10].

There are two critical factors contributing to the thermal conductivities of polymeric materials. One is the formation of heat conduction paths, another is the stacking density of the thermally conductive fillers in the composites [11]. Studies on filling thermally conductive fillers into polymer resin have been frequently reported so far. Ishida and Rimdusit [10] prepared polybenzoxazine filled with $\mathrm{BN}$ and achieved a thermal conductivity of $32.5 \mathrm{~W} \cdot(\mathrm{m} \cdot \mathrm{K})^{-1}$ when the filler loading was $88 \mathrm{wt} \%$. Kozako et al. [12] filled $\mathrm{Al}_{2} \mathrm{O}_{3}$ with a particle size of $10 \mu \mathrm{m}$ into epoxy resin and the thermal conductivity reached $4.3 \mathrm{~W} \cdot(\mathrm{m} \cdot \mathrm{K})^{-1}$ when the $\mathrm{Al}_{2} \mathrm{O}_{3}$ content was $60 \mathrm{vol} \%$. Shengtai $\mathrm{Zhou}$ [13] investigated the PA6/PC immiscible blends with a mass proportion of $7 / 3$ filled with graphite and got a thermal conductivity of $4.75 \mathrm{~W} \cdot(\mathrm{m} \cdot \mathrm{K})^{-1}$ at the graphite loading of $50 \mathrm{wt} \%$.

Graphene and carbon nanotubes have attracted much interests for the ultrahigh thermal conductivity of about 5000 and $3000 \mathrm{~W} \cdot(\mathrm{m} \cdot \mathrm{K})^{-1}$ respectively $[14,15]$. Graphene or carbon nanotubes filled polymers are considered to be very promising candidates for thermally conductive materials and expected to promote thermal conductivity at lower filler loading [16-18]. Zhang et al. [19] prepared PVDF filled with $10 \mathrm{wt} \%$ of carbon nanotubes and $1 \mathrm{wt} \%$ of oxidized graphene. The thermal conductivity of the composite reached $0.95 \mathrm{~W} \cdot(\mathrm{m} \cdot \mathrm{K})^{-1}$. Graphene and carbon nanotubes could enhance the thermal conductivity of polymer to some extent at lower filler content but far from meeting requirements. What is more, the high cost of graphene or carbon nanotubes arisen from the complicated preparation process [20] would severely restrict their application in industrial manufacture.
As we discussed, the filler content would still be an important factor to thermal conductivities of polymer materials in mass production. Although relatively high thermal conductivity was achieved at high filler loading, the processing of polymer would be difficult because of the high melt viscosity for large number of solid particles existing in the polymer melt, and the device abrasion would be unavoidable. As mentioned above, LMTM have low melting point and low viscosity under melting state. Compared with solid particles, LMTM fillers would be more beneficial to the processing of polymer composites. Zhang et al. [21] investigated the rheological properties of polymer/LMTM and found that the LMTM filler decreases the melt viscosity at temperatures above the melting point. Until now, most of the studies on Polymer/LMTM composites concentrated on enhancing the electrically conductive property [1-5]. For instance, Michaeli and Pfefferkorn [1] prepared electrically conductive PA6 with copper fibers and Sn$\mathrm{Zn}$ alloy which was molten during processing. So far, studies on the thermal conductivities of polymer/LMTM composites have been rarely reported [22, 23]. Suplicz and Kovács [22] developed thermally conductive polymer/LMTM composites which can be processed easily with injection molding.

However, the extremely low viscosity and ultrahigh surface tension of liquid metal compared with polymer melt [6, 24-26] would lead to serious agglomeration of LMTM. Thus the content and the dispersion of LMTM in polymer matrix would be severely restricted [27]. Mrozek et al. [5] studied on electrically conductive polymer composites based on nickel and low melting eutectic metal. They concluded that the addition of the nickel particulate is critical for maintaining eutectic dispersion. In this work, 
LMTM-Sn which has a thermal conductivity of $61.7 \mathrm{~W} \cdot(\mathrm{m} \cdot \mathrm{K})^{-1}[28]$ was introduced into PA6 to investigate the distribution of $\mathrm{Sn}$ and the thermal conductivity of PA6. Then, in dealing with the agglomeration of Sn, graphite was introduced into PA6/Sn composite to enhance the filler distribution and the thermal conductivity of the composite. Besides, the PA6/graphite composites were also prepared as control. The goal of this work is to develop a novel PA6 based material, which has a good thermal conduction.

\section{Experimental}

\subsection{Materials}

PA6 (UBE Nylon 1013b) with a density of $1.14 \mathrm{~g} / \mathrm{cm}^{3}$ was obtained from UBE Engineering Plastics, S.A. (Japan). Flake graphite (F-2, Hexagonal structure, Standard No: Q/GHYP1-2012) with an average size of $15 \mu \mathrm{m}$ and carbon content of $99 \%$ was purchased from Shanghai Yifan graphite co., LTD (China). The Sn powder (300 mesh) with a melting point of $231.9^{\circ} \mathrm{C}$ and prepared by electrolysis was purchased from Zhengzhou Hengchang metal materials co., LTD. (China). The component of Sn powder is listed in Table 1. All of the properties data were provided by the manufactures.

\subsection{Preparation of PA6/Sn, PA6/graphite and PA6/graphite/Sn composites}

Prior to blending, the PA6 pellets and graphite were dried at $80^{\circ} \mathrm{C}$ for $10 \mathrm{~h}$, while Sn powder was dried under vacuum at $80^{\circ} \mathrm{C}$ for $5 \mathrm{~h}$. The raw materials and fillers without any modification were premixed in plastic bags by drastically shaking manually. The materials designation and the detailed formulations of PA6/graphite, PA6/Sn and PA6/graphite/Sn composites are shown in Table 2. The composites systems were fabricated using a Haake twin-screw extruder (polylab OS 16/40, Germany). The extruding temperatures were set as 220, 250, 250, 270, 270, 270, 270, $270,250,230^{\circ} \mathrm{C}$ (from feeding section $\left(T_{1}\right)$ to extruding die $\left.\left(T_{10}\right)\right)$. The screw speed was set as $60 \mathrm{r} / \mathrm{min}$. Then the extrudates were pelletized and dried under vacuum for $10 \mathrm{~h}$ at $80^{\circ} \mathrm{C}$. Then the pellets were molded into circular plate samples with a diameter of $12.7 \mathrm{~mm}$ (and a thickness of $2 \mathrm{~mm}$ ) and rectangular samples with a dimension of $80 \times 10 \times 4 \mathrm{~mm}$ via an ONLY injection molding machine (P Series $50 \mathrm{e}$,
Table 1. Component of Sn powder

\begin{tabular}{|c|c|c|c|c|c|c|c|}
\hline $\begin{array}{c}\text { Sn content } \\
{[\geq \%]}\end{array}$ & \multicolumn{7}{|c|}{$\begin{array}{c}\text { Impurity content } \\
{[\leq \%]}\end{array}$} \\
\cline { 2 - 8 } & $\mathbf{F e}$ & $\mathbf{P b}$ & $\mathbf{C u}$ & $\mathbf{S}$ & $\mathbf{B i}$ & $\mathbf{A s}$ & $\mathbf{S b}$ \\
\hline 99.50 & 0.04 & 0.10 & 0.02 & 0.001 & 0.03 & 0.01 & 0.04 \\
\hline
\end{tabular}

Table 2. Materials designation and detailed formulations

\begin{tabular}{|c|c|c|c|c|}
\hline Component & Designation & $\begin{array}{c}\text { PA6 } \\
{[w t \%]}\end{array}$ & $\begin{array}{c}\text { Graphite } \\
\text { [wt\%] }\end{array}$ & $\begin{array}{c}\text { Sn } \\
{[w t \%]}\end{array}$ \\
\hline \multirow{5}{*}{ PA6/graphite } & G10 & 90 & 10 & 0 \\
\hline & G20 & 80 & 20 & 0 \\
\hline & G30 & 70 & 30 & 0 \\
\hline & G40 & 60 & 40 & 0 \\
\hline & G50 & 50 & 50 & 0 \\
\hline \multirow{5}{*}{ PA6/Sn } & S04 & 96 & 0 & 4 \\
\hline & S08 & 92 & 0 & 8 \\
\hline & S12 & 88 & 0 & 12 \\
\hline & S16 & 84 & 0 & 16 \\
\hline & S20 & 80 & 0 & 20 \\
\hline \multirow{5}{*}{ PA6/graphite/Sn } & GS04 & 46 & 50 & 4 \\
\hline & GS08 & 42 & 50 & 8 \\
\hline & GS12 & 38 & 50 & 12 \\
\hline & GS16 & 34 & 50 & 16 \\
\hline & GS20 & 30 & 50 & 20 \\
\hline
\end{tabular}

China). The injection temperatures were set as 220 , $270,270,270{ }^{\circ} \mathrm{C}$ (from feeding zone to nozzle). The injection pressure, injection rate, holding pressure, backpressure, mold temperature and cooling time were set as $30 \mathrm{MPa}, 40 \mathrm{~mm} / \mathrm{s}, 20 \mathrm{MPa}, 3 \mathrm{MPa}, 28^{\circ} \mathrm{C}$ and 20 s respectively.

\subsection{Characterization}

\subsubsection{Morphology and element distribution}

The circular plate samples were cryogenically fractured in liquid nitrogen along the red arrow as shown in Figure 2a to observe the filler distribution. Then the fractured surfaces were coated with a gold layer before the observation. The fractured surface morphology of the composites was observed via an en-

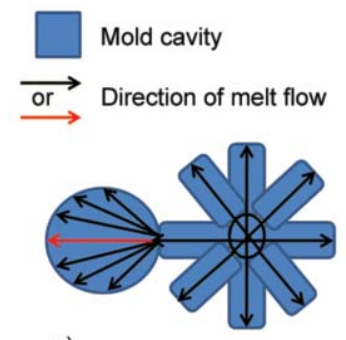

a)

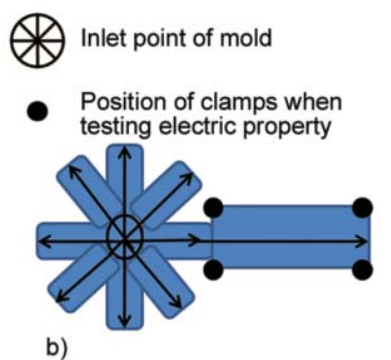

b)
Figure 2. Sketch maps of melt flow in the mold ((a) for circular samples and (b) for rectangular samples) 
vironmental scanning electron microscope (ESEM, Quanta 200, FEI, Holland) with an acceleration voltage of $10 \mathrm{kV}$ in high vacuum mode. The element distribution images of Sn were obtained via Energy Disperse Spectroscopy (EDS) which was an accessory of the ESEM.

\subsubsection{Thermal conductivity measurement}

The circular plate samples with a diameter of $12.7 \mathrm{~mm}$ and a thickness of $2 \mathrm{~mm}$ were used for the test of thermal diffusivity (through-plane) by Netzsch (Germany) laser flash thermal diffusivity apparatus (LFA 447 NanoFlash) at $30^{\circ} \mathrm{C}$. The apparatus fires a laser pulse on the bottom surface of the sample, then the temperature variation of the top surface is detected and the thermal diffusivity is calculated according to the temperature variation. The test mode and calculation model were set as single layer and Cowan+pulse respectively. Calculation range was 10 times of halfheating up time. The specific heat capacity of the sample at $30^{\circ} \mathrm{C}$ were determined via Netzsch (Germany) differential scanning calorimeter (DSC-200 F3). The density was measured by water displacement method and the value was taken from the average of three samples. Then, the thermal conductivity $\kappa\left[\mathrm{W} \cdot(\mathrm{m} \cdot \mathrm{K})^{-1}\right]$ was calculated using Equation (1) [29]:

$\kappa=\rho \cdot \alpha \cdot C_{\mathrm{p}}$

where $\rho$ is the density $\left[\mathrm{g} / \mathrm{cm}^{3}\right], C_{\mathrm{p}}$ is the specific heat capacity $\left[\mathrm{J} \cdot(\mathrm{g} \cdot \mathrm{K})^{-1}\right]$, and $\alpha$ is the thermal diffusivity $\left[\mathrm{mm}^{2} / \mathrm{s}\right]$.

\subsubsection{Electrical conductivity measurement}

Rectangular samples $(80 \times 10 \times 4 \mathrm{~mm})$ were used for resistivity measurement. The electrical resistance $R$ $[\Omega]$ was determined by an electrometer (Keithley (USA) 2611B SYSTEM SourceMeter ${ }^{\circledR}$ ), which measures the electrical resistance according to the voltage applied on the sample and electric current flow through it. The four clamps of the electrometer were fixed on the four corners of the rectangle sample as shown in Figure 2b. The sweep voltage was set from 20 to $50 \mathrm{~V}$ and sweep type was set as linear. The $R$ value was the average taken from 5 specimens. Then the electrical resistance $R$ was converted into volume conductance $\sigma[\mathrm{S} / \mathrm{m}]$ with Equation (2):

$\sigma=\frac{1}{\rho}=\frac{L}{R S}$ where $L[\mathrm{~m}]$ is the distance (along the length direction of the sample) between clamps, $\rho[\Omega \cdot \mathrm{m}]$ is the volume resistivity, and $S\left[\mathrm{~m}^{2}\right]$ is the cross-sectional area of the sample.

\subsubsection{Differential scanning calorimetry (DSC)}

The crystallization and melting behavior of the composites were measured using a Netzsch (Germany) differential scanning calorimeter (DSC-200 F3). Experiments were performed with about $15 \mathrm{mg}$ samples under nitrogen atmosphere. The samples were firstly heated to $270^{\circ} \mathrm{C}$ at a rate of $20^{\circ} \mathrm{C} / \mathrm{min}$ to eliminate thermal history and then held at $270^{\circ} \mathrm{C}$ for $2 \mathrm{~min}$. Subsequently, the samples were cooled at a rate of $10^{\circ} \mathrm{C} / \mathrm{min}$ to $20^{\circ} \mathrm{C}$ and held at $20^{\circ} \mathrm{C}$ for $2 \mathrm{~min}$, then scanned from 20 to $270^{\circ} \mathrm{C}$ at a rate of $10^{\circ} \mathrm{C} / \mathrm{min}$. The crystallization and melting temperatures were obtained from the cooling and re-heating curves respectively. The crystallinity $\left(\chi_{c}\right)[\%]$ of the composites was calculated with Equation (3):

$\chi_{\mathrm{c}}=\frac{\Delta H_{\mathrm{m}}}{(1-\omega) \Delta H_{\mathrm{m}}^{\prime}}$

where $\Delta H_{\mathrm{m}}[\mathrm{J} / \mathrm{g}]$ is the melting enthalpy of the composite and $\omega[\mathrm{wt} \%]$ is the weight fraction of fillers. Besides, $\Delta H_{\mathrm{m}}^{\prime}[\mathrm{J} / \mathrm{g}]$ is the melting enthalpy of $100 \%$ crystalline PA6 and we adopted $230 \mathrm{~J} / \mathrm{g}$ [30].

\subsubsection{Thermal stability of the composites}

The thermal stability of the composites was characterized by a thermogravimetric analyzer (TGA Q5000, TA Instrument, U.S.A.). All measurements were performed under nitrogen gas condition with a flow rate of $25 \mathrm{~mL} / \mathrm{min}$ from 30 to $700^{\circ} \mathrm{C}$ at a heating rate of $10^{\circ} \mathrm{C} / \mathrm{min}$.

\section{Results and discussion}

\subsection{Morphology and element distribution}

The fractured surface morphology of the composites filled with graphite as single filler are shown in Figure 3. The pictures demonstrate an incremental mass ratio of graphite in the matrix from $30 \mathrm{wt} \%$ (17.6 vol\%) to $50 \mathrm{wt} \%$ (33.3 vol\%). Graphite particles were oriented along the processing flow direction (Figure 3), consistent with Amesöder et al.'s [31] results. It is ascribed to the processing methodinjection molding. The graphite flakes would parallel to the direction of melt flow (as shown in Figure 2) 


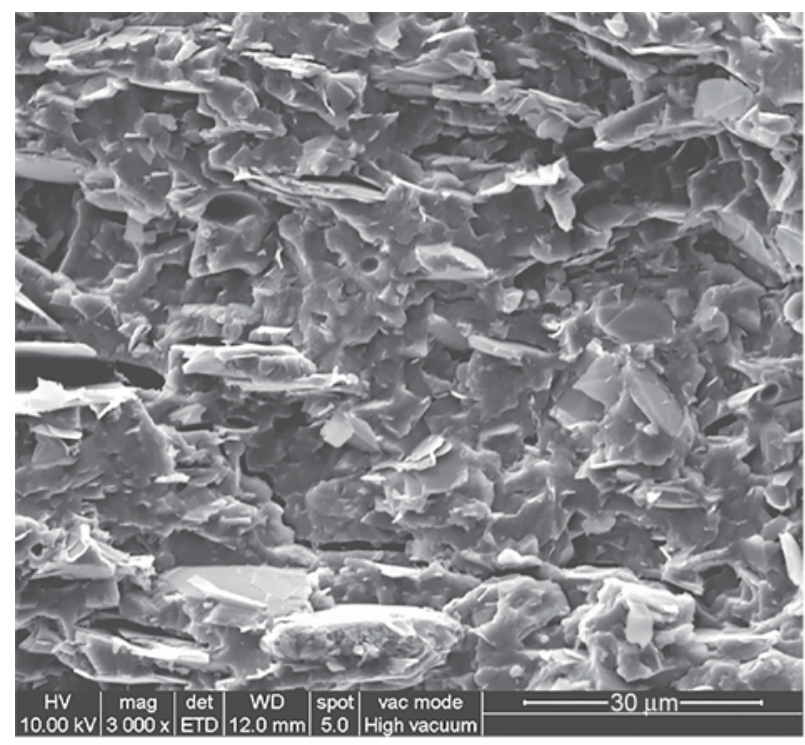

a)

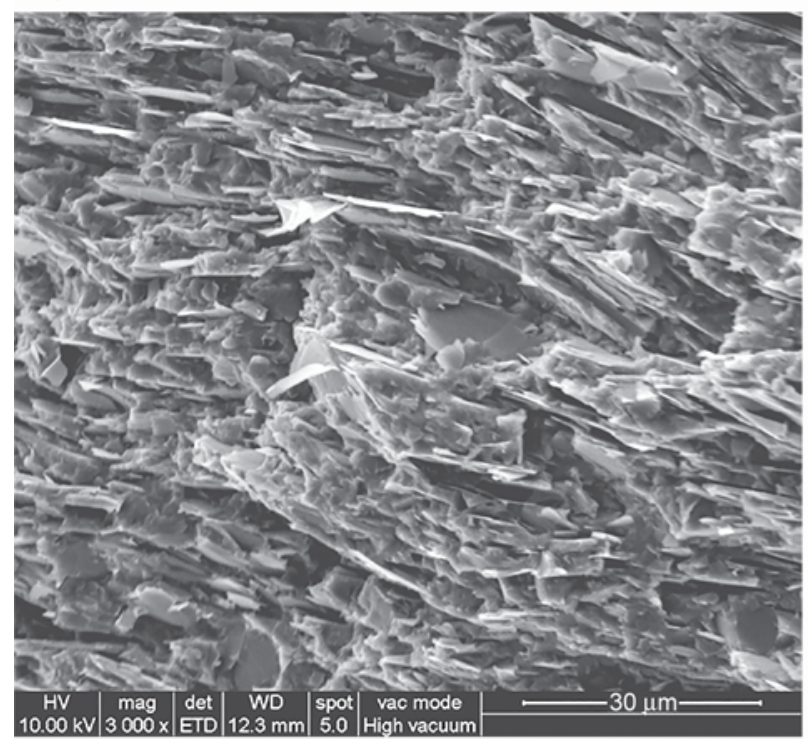

c)

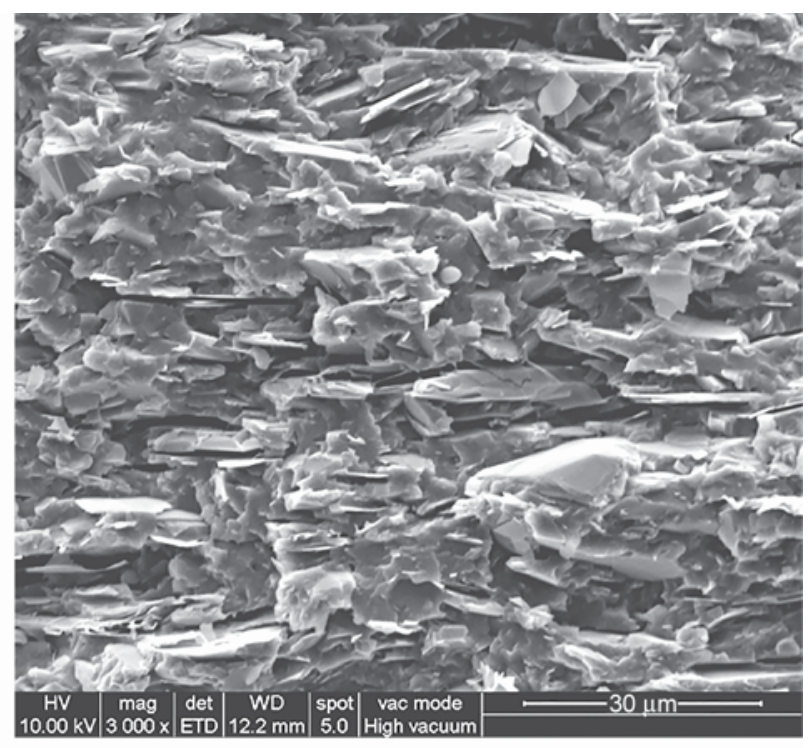

b)

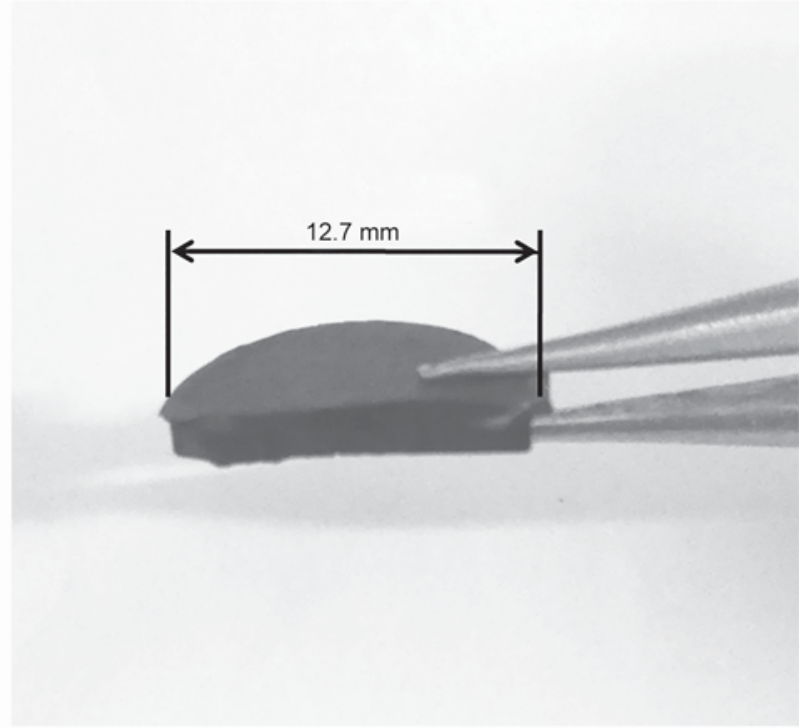

d)

Figure 3. SEM images of the surfaces of the cryogenically fractured composites ((a) for G30, (b) for G40 and (c) for G50). (All the micrograph were obtained from the fractured surfaces of the samples as shown in (d)).

to make the least flow resistance. It is obvious that graphite particles disperse discretely in the matrix and the space between graphite particles is relatively larger when the graphite content is $30 \mathrm{wt} \%$ $(17.6 \mathrm{vol} \%)$. With the increase of graphite content, the space between graphite particles reduces. When the graphite content reaches $50 \mathrm{wt} \%$ (33.3 vol\%), the graphite particles have already interconnected together and a network structure consisted of flake graphite particles has already been formed.

However, when adding Sn as single filler into PA6 matrix, the agglomeration of Sn could be easily observed with naked eyes in Figure $4 a, b$ and c. The agglomeration of Sn could be clearly observed from SEM images as shown in the red frames in Figure 4d, e and $\mathrm{f}$. With the increase of the Sn content, the agglomerate size increases gradually. When the $\mathrm{Sn}$ content is $20 \mathrm{wt} \%$ (3.79 vol\%) the agglomerate size reaches about $70 \mu \mathrm{m}$. This is mainly ascribed to the extremely low viscosity (1.4-1.8 $\mathrm{mPa} \cdot \mathrm{s}$ during 500 $600 \mathrm{~K})$ [6] and ultrahigh surface tension (400$620 \mathrm{mN} / \mathrm{m}$ during 400-1600 K) [22] for liquid metal versus the high viscosity (about $100 \mathrm{~Pa} \cdot \mathrm{s}$ during shear rate of 100-1000/s) [24] and low surface tension (lower than $40 \mathrm{mN} / \mathrm{m}$ at $230{ }^{\circ} \mathrm{C}$ ) [23] for polymer melt, which leads to poor compatibility between PA6 and $\mathrm{Sn}$. The fact that Sn has good flowability and a strong trend of shrinking superficial area in the state of liquid leads to serious agglomeration in the PA6 matrix. Another reason for the agglomeration is that 


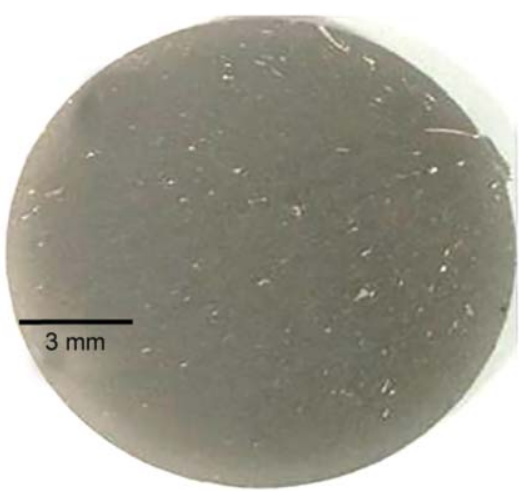

a)

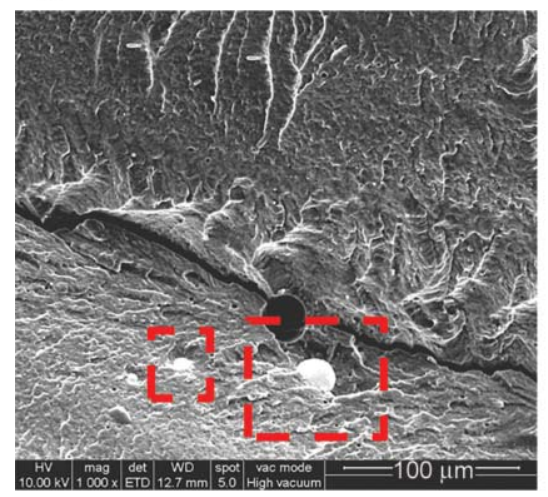

d)

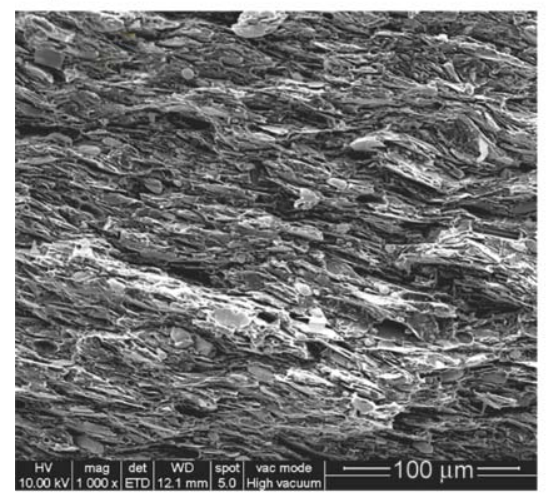

g)

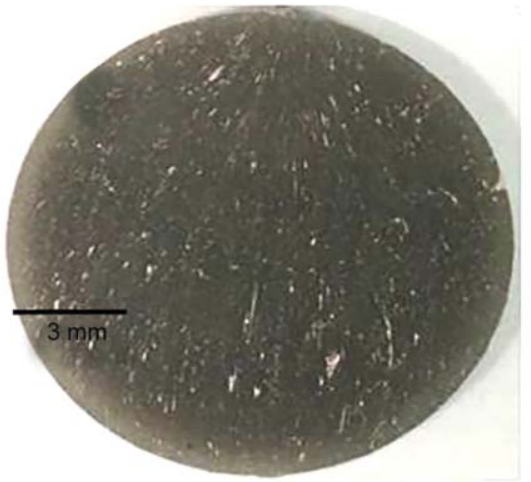

b)

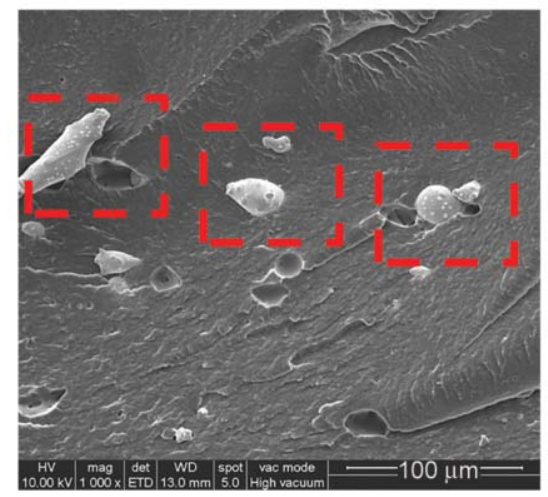

e)

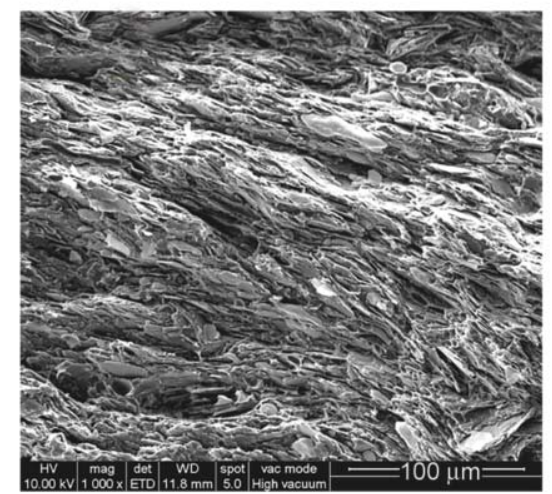

h)

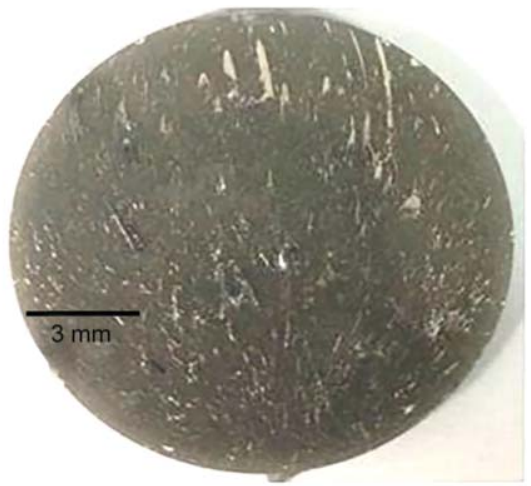

c)

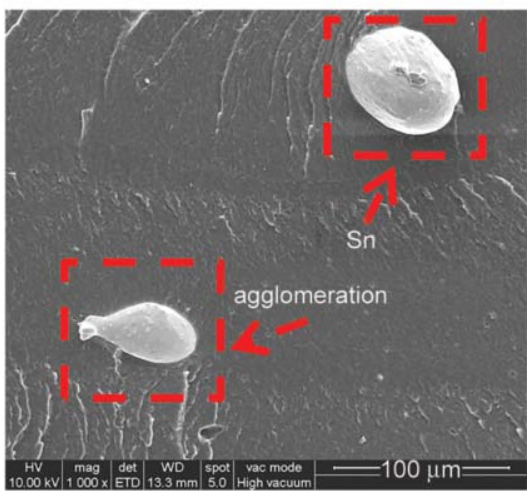

f)

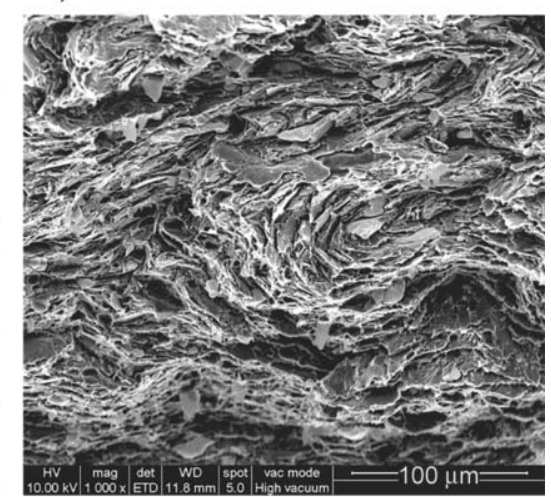

i)

Figure 4. Digital photos of the composites ((a) for S12, (b) for S16 and (c) for S20) and SEM images of the surfaces of cryogenically fractured composites ((d) for S12, (e) for S16, (f) for S20, (g) for GS12, (h) for GS16 and (i) or GS20)

metal and organic polymer have different chemical and physical properties, thus they have poor compatibility.

The SEM images of the composites filled with $50 \mathrm{wt} \%$ of graphite and Sn content various from $12 \mathrm{wt} \%$ (2.91 vol\%) to $20 \mathrm{wt} \%$ (5.42 vol\%) as hybrid fillers are shown in Figure $4 \mathrm{~g}$, $\mathrm{h}$ and i. It could be observed that there is no agglomerate even the $\mathrm{Sn}$ content reaches $20 \mathrm{wt} \%$ (5.42 vol\%). And most of the flake graphite particles in GS12 and GS16 are oriented along the direction of the melt flow as well. Interestingly, the distribution form of flake graphite in GS20 is circinate. This is due to the existence of friction between graphite particles. With the increase of weight fraction of $\mathrm{Sn}$, the volume fraction of graphite particles (50 wt \%) increases because the density of $\mathrm{Sn}$ is much higher than that of graphite. The increase of the volume fraction of graphite particles leads to the increase of the friction between graphite particles and the poor flowability of the polymer melt, which leads to decrease of orientation degree of flake graphite particles in GS20.

Figure 5 shows the EDS images of Sn in S20 and GS20. The Sn in S20 concentrates together and forms spherical-like agglomerate (Figure 5a), while the distribution of Sn in GS20 is much more uniform as 

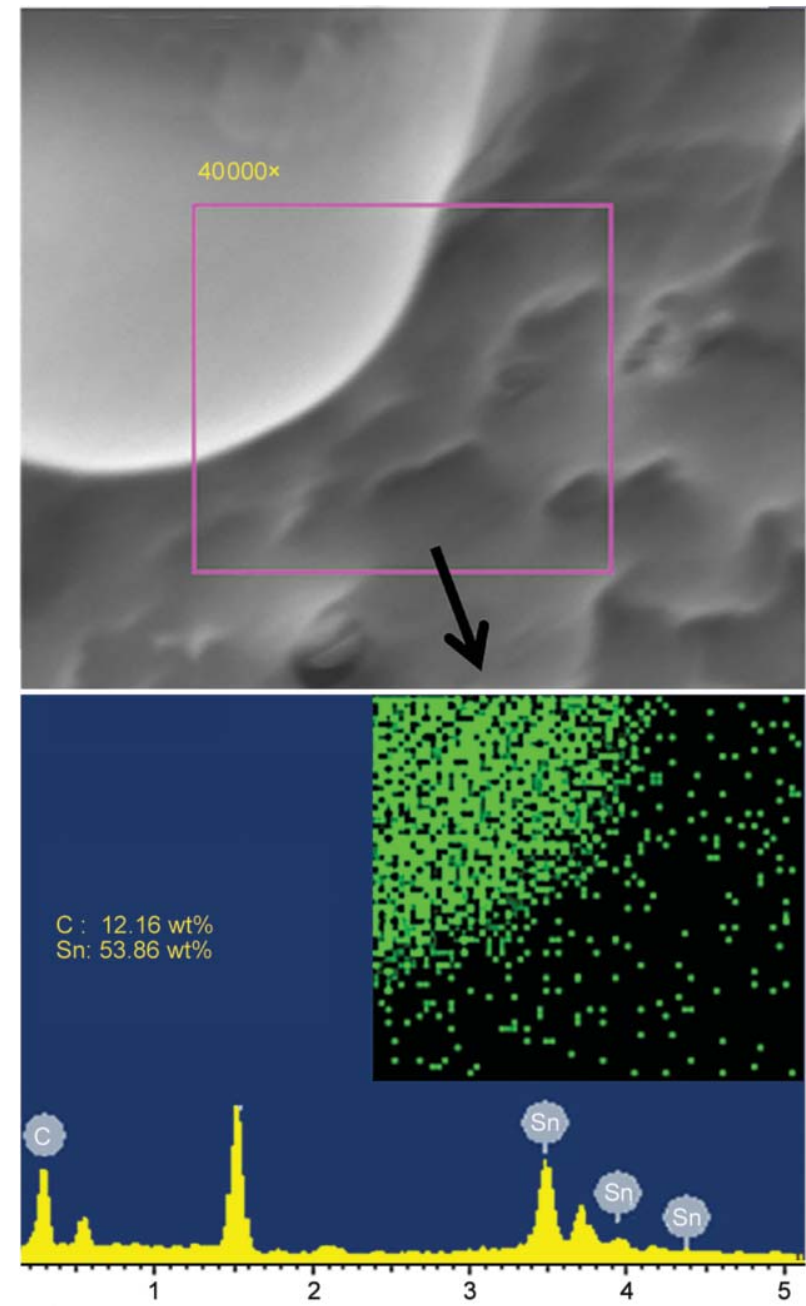

a)

Figure 5. EDS images of Sn in (a) S20 and (b) GS20

shown in Figure 5b. The reason why Sn could disperse well in GS20 may be the fact that the flowability of liquid $\mathrm{Sn}$ is hindered by the solid graphite particles. Thus the encounter chance of Sn fluid decreases for the decline of liquidity, which leads to the decrease of agglomeration. Besides, the even dispersion of $\mathrm{Sn}$ is speculated to be related to the interaction between $\mathrm{Sn}$ and graphite, which will be discussed in the part of DSC measurements.

\subsection{Thermal conductivities of the composites}

The thermal conductivities of PA6/graphite composites are shown in Figure 6a. The thermal conductivity increases slowly as a function of graphite content below $25.0 \mathrm{vol} \%$ (40 wt $\%$ ). And a sharp increase appears when the graphite content exceeds $25.0 \mathrm{vol} \%$ (40 wt\%). The flake graphite particles could occupy enough volume in the PA6 matrix to contact each other and form the thermally conductive networks (Figure 3) when the graphite content exceeds

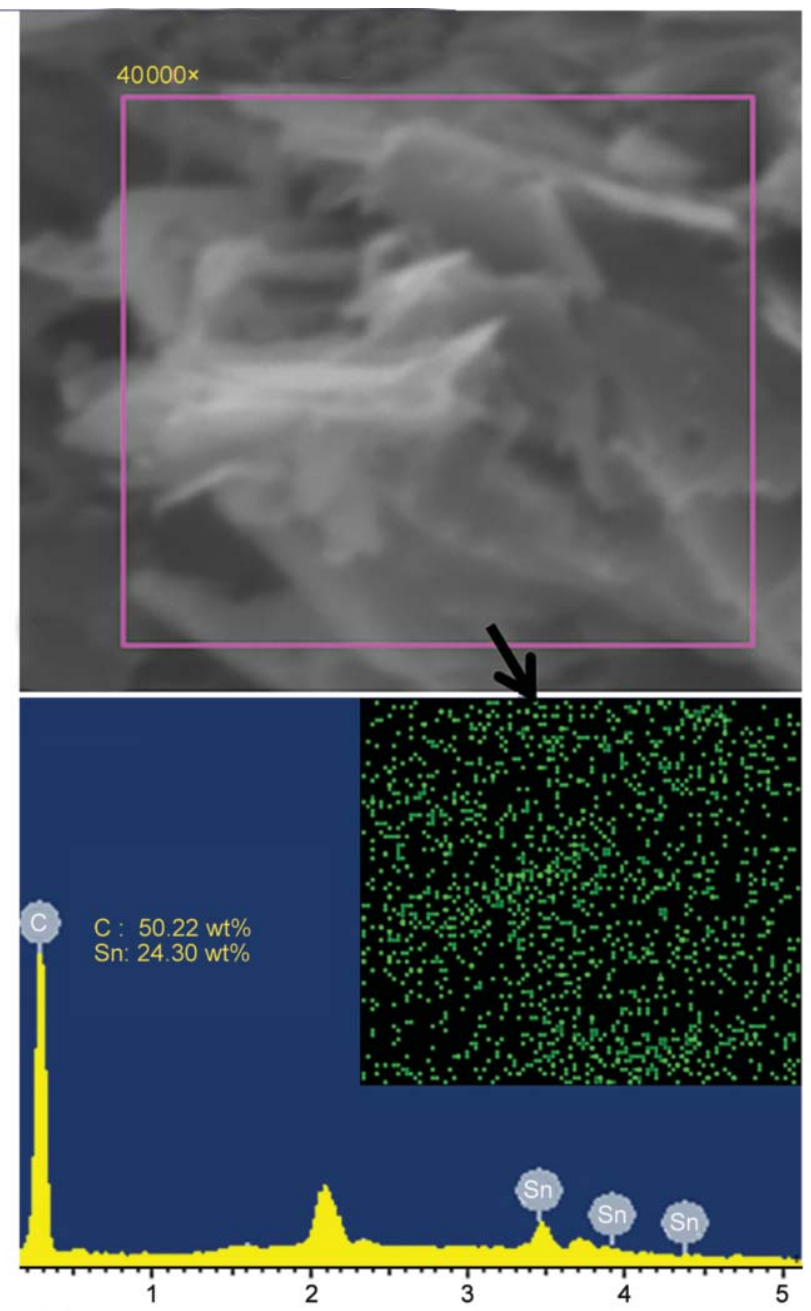

b)

$25.0 \mathrm{vol} \%$ ( $40 \mathrm{wt} \%$ ), and the thermal energy could pass through quickly along the thermally conductive networks. The thermal conductivity of PA6/graphite (33.3 vol\%) composite reaches $1.852 \mathrm{~W} \cdot(\mathrm{m} \cdot \mathrm{K})^{-1}$, agreeing with Amesöder et al. [31]. However, there is almost no increase in the thermal conductivities of the PA6/Sn composites as shown in Figure 6b. There are two main reasons for this phenomenon, one is that the Sn content is not enough to form conductive networks. Another is that the distribution of $\mathrm{Sn}$ is extremely non-uniform in the matrix (Figure 4a$\mathrm{f}$ and Figure 5a), which would give rise to high thermal resistance at the interface between filler and polymer matrix $[32,33]$.

When adding Sn into PA6/graphite composite, the thermal conductivities increase obviously as shown in Figure $6 \mathrm{~b}$. The thermal conductivity reaches $3.879 \mathrm{~W} \cdot(\mathrm{m} \cdot \mathrm{K})^{-1}$ when the Sn content is $4.10 \mathrm{vol} \%$ $(16 \mathrm{wt} \%)$ versus $1.852 \mathrm{~W} \mathrm{~W} \cdot(\mathrm{m} \cdot \mathrm{K})^{-1}$ for $\mathrm{G} 50$ and $0.297 \mathrm{~W} \cdot(\mathrm{m} \cdot \mathrm{K})^{-1}$ for the virgin PA6. This is ascribed 

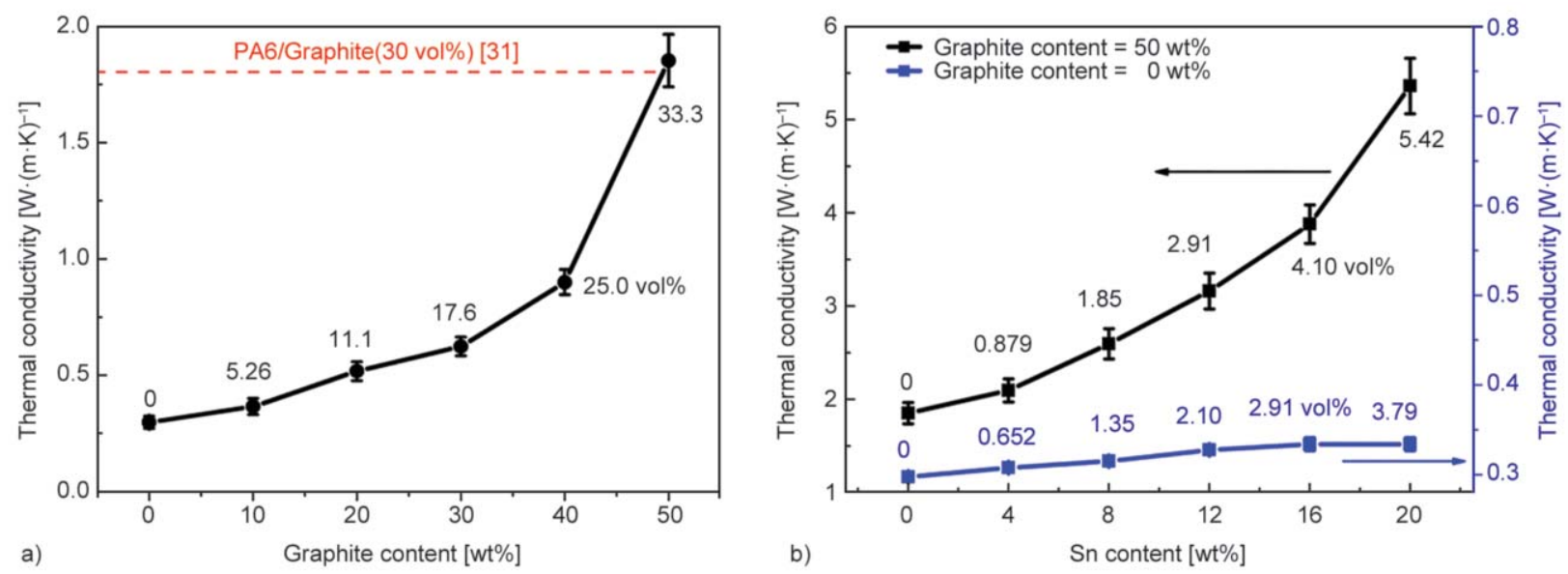

Figure 6. Thermal conductivities of (a) PA6/graphite composites, (b) PA6/Sn and PA6/graphite(50 wt \%)/Sn composites as a function of filler content. (The values beside every data point refer to the volume fraction [vol\%] of graphite (a) and Sn (b)in the corresponding composites).

to four reasons, one is that $\mathrm{Sn}$ is high conductive filler with a thermal conductivity of $61.7 \mathrm{~W} \cdot(\mathrm{m} \cdot \mathrm{K})^{-1}[28]$ and the distribution of $\mathrm{Sn}$ is uniform in the composites under the effect of graphite particles. The second is that the increase of the volume fraction of graphite is accompanied by the addition of Sn, while the weight fraction of graphite remains $50 \mathrm{wt} \%$ as discussed in the part of 3.1 (Morphology and element distribution). The thermally conductive networks become strong because the volume occupied by graphite is increased. The third, graphite particles could be more uniform dispersed in matrix for the $\mathrm{Sn}$, which is in a state of low viscosity liquid [6] when processed under high temperature. The fourth, the interaction between Sn and graphite is speculated to be related to the high thermal conductivity (discussed in the part of DSC measurements). The thermal conductivity of the composite sharply increases to $5.364 \mathrm{~W} \cdot(\mathrm{m} \cdot \mathrm{K})^{-1}$ when the Sn content reaches 5.42 vol\% (20 wt $\%$ ). This is associated with the microstructure of the composite and the test method we adopted. The through plane thermal conductivities were tested in this study, and Figure 4i shows that the distribution form of flake graphite in GS20 is circinate. Indicating that the number of graphite flakes along the perpendicular direction of the plate samples increases. It has been reported that the thermal conductivity along the graphite layers is much larger than that of cross layers [34, 35]. We could conclude that the Sn has a synergistic effect with graphite on the improvement of the thermal conductivity of PA6.

\subsection{Electrical conductivities of PA6/graphite and PA6/graphite/Sn composites}

The log electrical conductivities $(\sigma)$ values are plotted as a function of filler content in Figure 7. It is easy
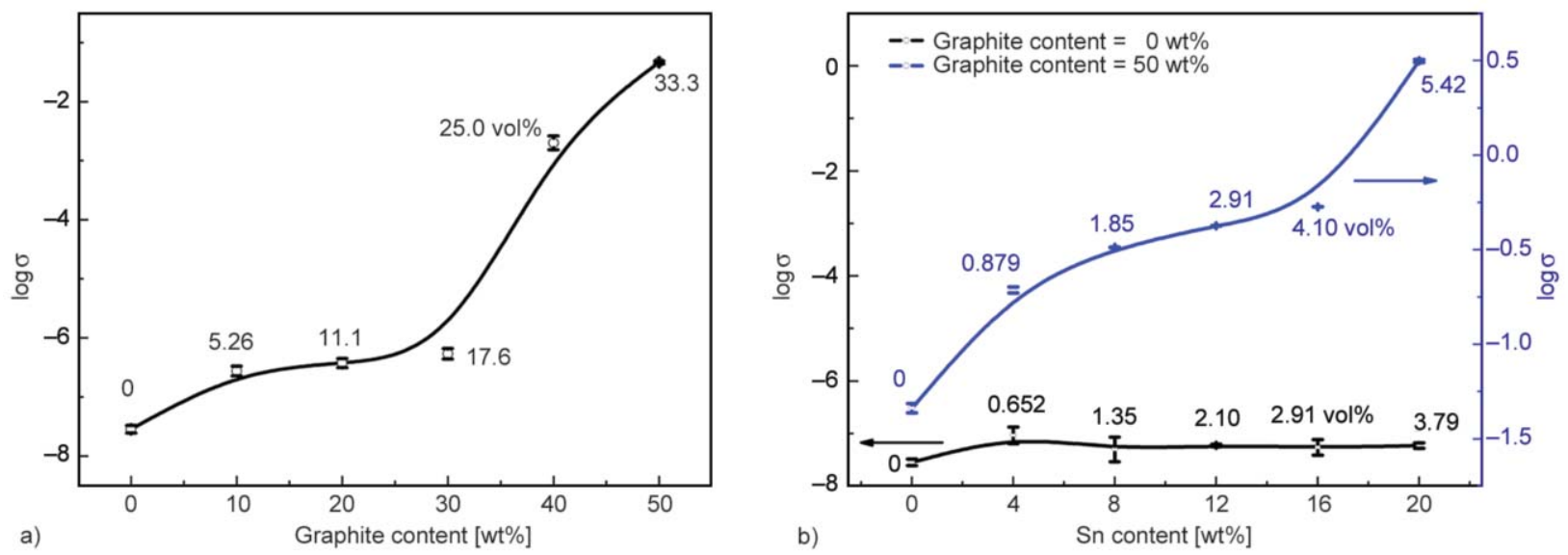

Figure 7. Electrical conductivities ( $\sigma$ ) of (a) PA6/graphite composites and (b) PA6/graphite(50 wt\%)/Sn composites and PA6/Sn composites as a function of filler content. (The values beside every data point refer to the volume fraction [vol\%] of graphite (a) and Sn (b) in the corresponding composites). 
to understand that the $\sigma$ increase as a function of filler content, except that the $\log \sigma$ of PA6/Sn remain almost constant because of the poor distribution of $\mathrm{Sn}$ (Figure 7b). Notably, the sharp increase of $\sigma$ of PA6/ graphite composites occurs during the graphite content between $17.6 \mathrm{vol} \%$ (30 wt $\%$ ) and $25.0 \mathrm{vol} \%$ (40 wt $\%$ ), while the thermal conductivity increases sharply between $25.0 \mathrm{vol} \%$ (40 wt $\%$ ) and $33.3 \mathrm{vol} \%$ $(50 \mathrm{wt} \%)$. It is probably ascribed to that the conductive networks are easy to form along the direction of melt flow (Figure 2b) because of the orientation of graphite flakes (Figure 3). And the test method we adopted just detected the $\sigma$ in the direction of melt flow as described before. Moreover, field emission theory [36] believes that the huge electric field existing between conductive particles would induce the occurrence of field emission when the conductive particles close to $10 \mathrm{~nm}$ or more closer, even though there is insulation layer between the conductive particles. Thus
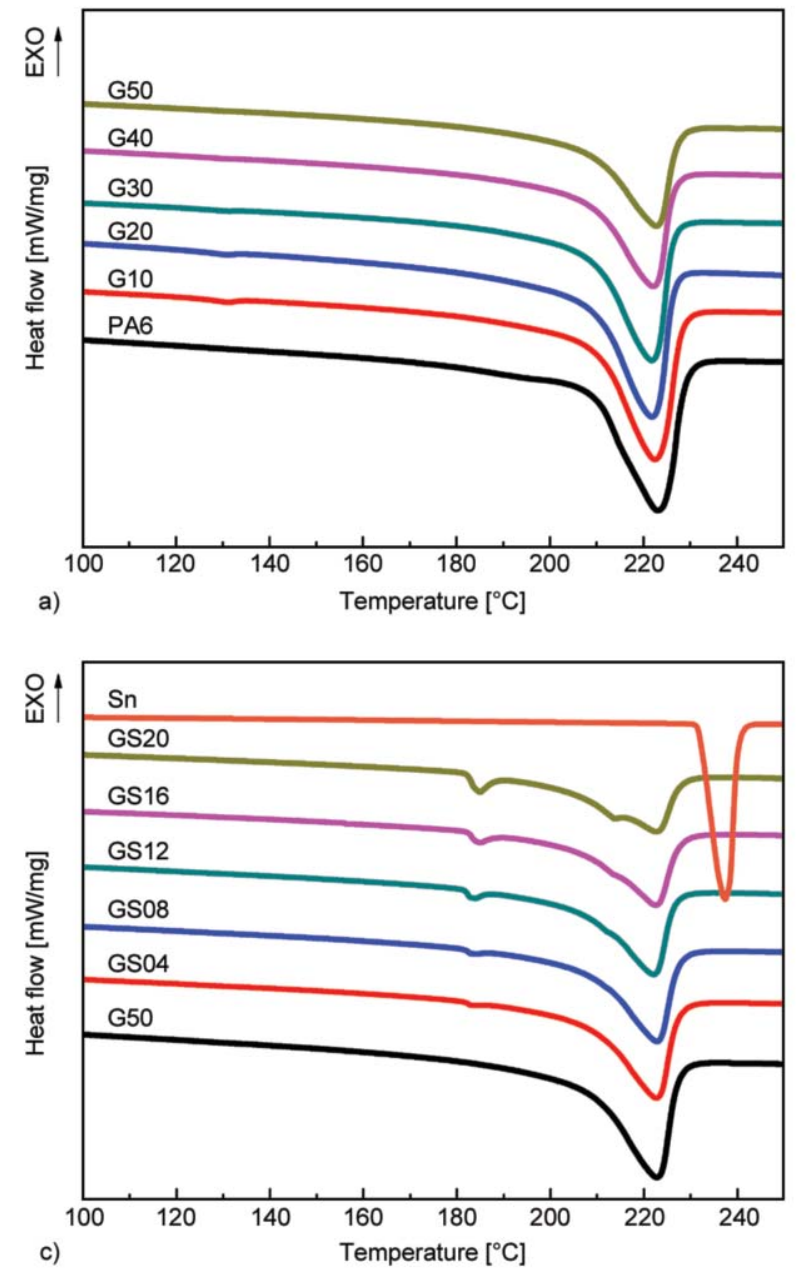

the electricity could happen without the contact of graphite particles. The electrical conductivity of PA6 increased nearly 8 orders of magnitude at the maximum filler content.

\subsection{DSC measurements}

The DSC curves of the composites are shown in Figure 8. For clarity, the vertical distance of the curves is enlarged. And Table 3 shows related DSC data of the PA6/graphite composites. Figure 8a shows that

Table 3. DSC data for the cooling procedure and the re-heating procedure

\begin{tabular}{|c|c|c|c|c|}
\hline Samples & $\begin{array}{c}\boldsymbol{T}_{\mathbf{c}} \\
{\left[{ }^{\circ} \mathbf{C}\right]}\end{array}$ & $\begin{array}{c}\boldsymbol{T}_{\mathbf{m}} \\
{\left[{ }^{\circ} \mathbf{C}\right]}\end{array}$ & $\begin{array}{c}\Delta \boldsymbol{H}_{\mathbf{m}} \\
{[-\mathbf{J} / \mathbf{g}]}\end{array}$ & $\begin{array}{c}\chi_{\mathbf{c}} \\
{[\mathbf{\%}]}\end{array}$ \\
\hline PA6 & 188.3 & 223.5 & 47.72 & 20.8 \\
\hline G10 & 193.3 & 222.1 & 45.31 & 21.9 \\
\hline G20 & 194.9 & 222.2 & 41.25 & 22.4 \\
\hline G30 & 195.4 & 221.4 & 42.14 & 26.2 \\
\hline G40 & 195.5 & 222.6 & 36.30 & 26.3 \\
\hline G50 & 195.1 & 222.4 & 32.20 & 28.0 \\
\hline
\end{tabular}
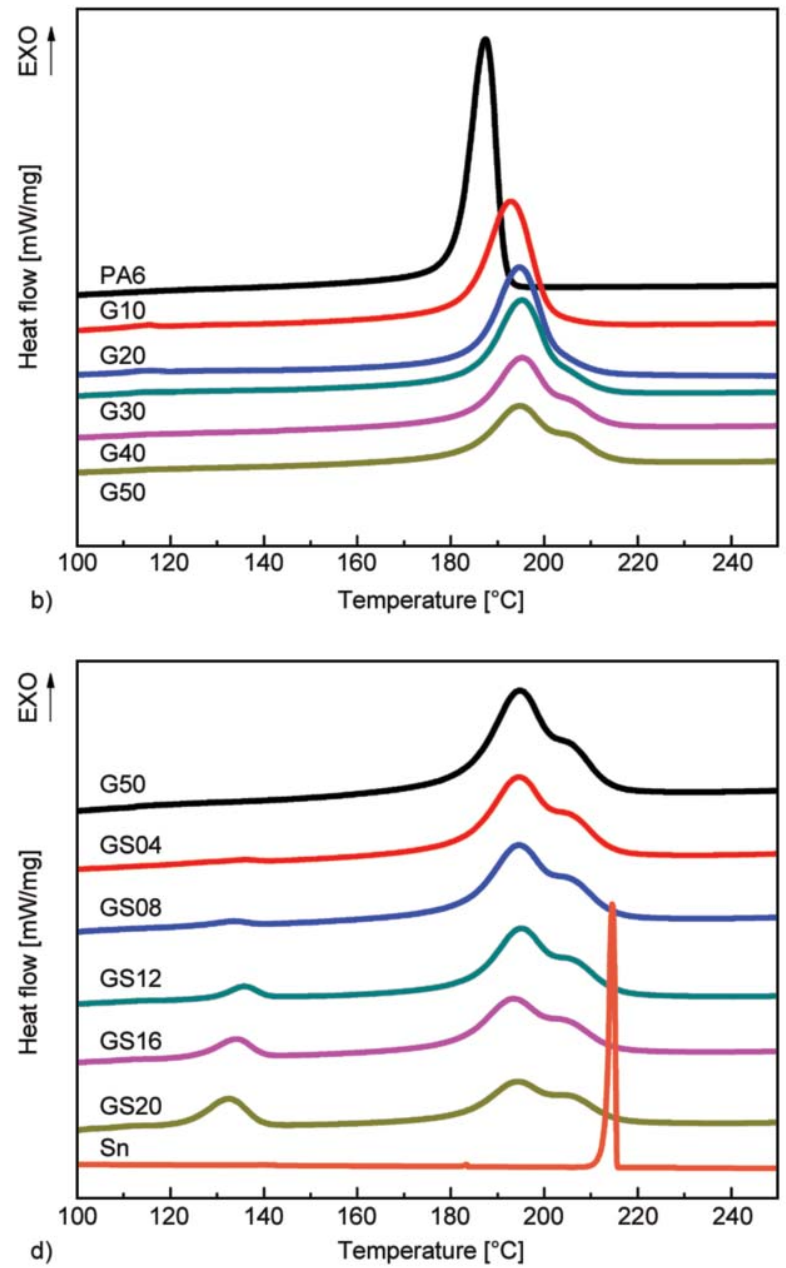

Figure 8. (a) Second-heating curves obtained from PA6/graphite composites, (b) cooling curves obtained from PA6/graphite composites, (c) second-heating curves obtained from Sn and PA6/graphite(50 wt\%)/Sn composites, (d) cooling curves obtained from $\mathrm{Sn}$ and PA6/graphite $(50 \mathrm{wt} \%) / \mathrm{Sn}$ composites 
all the samples exhibit strong melting peaks at about $220^{\circ} \mathrm{C}$, corresponding to the melting event of $\alpha$-form crystals of PA6 $[37,38]$. It is evident that the incorporation of graphite has little effect on the melting behavior of the composites except the decrease of $\Delta H_{\mathrm{m}}$. Unlike the melting behavior of the composites, the crystallization process is greatly affected by the introduction of graphite. It could be observed from Figure $8 \mathrm{~b}$ and Table 3 that the crystallization temperature and crystallinity of the composites increase with the addition of graphite. This could be ascribed to the facilitating effect of graphite particles which act as nucleating agent on the crystallization of PA6 [3941]. It is interesting to observe that the new peaks on the exotherms of PA6/graphite composites appear at higher temperature with the increasing amount of graphite content. Similar appearance of exotherms with double peaks in PA6/MWNTs composites was reported before [42-44]. The appearance of higher crystallization temperature is related to the increase of graphite content. More heterogeneous nucleation sites are available with the increasing amount of graphite particles. Therefore, the crystallization of polymer chains could occur at higher temperature and different morphology of crystals might be induced by the large number of graphite particles [42, 43].

As to the thermal behavior of PA6/graphite/Sn composites, it is interesting to observe from Figure $8 \mathrm{c}$ that two small endothermic peaks gradually expand with the increase of Sn content at about 180 and $210^{\circ} \mathrm{C}$ respectively. It is also found from Figure $8 \mathrm{~d}$ that a range of peaks on the exotherms of PA6/graphite/Sn composites at about $135^{\circ} \mathrm{C}$ become stronger with the increase of Sn content. However, the melting peak and exotherm of pure $\mathrm{Sn}$ is not observed from DSC curves of PA6/graphite/Sn composites (Figure 8c and d). It is obvious that the unusual fact is relative to the special heat effect of Sn under the existence of graphite. As is well known, Sn melt consists of Sn ions and free electrons $\left(e_{\mathrm{f}}\right)$. Large number of $\mathrm{Sn}$ ions arrange neatly and form the close packing when crystallizing alone, while free electrons distribute around nucleus, shared by large number of Sn ions [45, 46]. However, there are abundant $\pi$ electrons $\left(e_{\pi}\right)$ arising from $\pi$-bonds of carbon atoms moving along the graphite layers. The $e_{\pi}$ could move freely along the corresponding carbon atomic layers, which resembles to $e_{\mathrm{f}}$. Thus we suppose that the crystallization of Sn would be affected by $e_{\pi}$ under the existence of graphite particles. As shown in Figure 9, the Sn ions may be strongly attracted by numerous $e_{\pi}$ and distribute evenly around graphite layers when Sn melt flows through graphite layers. The free electrons participate in the conjugated system of graphite layers to keep electric neutrality. Unlike crystallization of pure $\mathrm{Sn}$, the $\mathrm{Sn}$ ions loosely arrange when crystallizing since there is not enough $\mathrm{Sn}$ ions around a certain site because of the strong attraction of $e_{\pi}$. Thus the electron transfer between graphite and Sn occurs. Lots of reports about electron transfer between metal and carbon materials were reported before [47-50]. The endothermic peaks (Figure 8c) at about 180 and $210^{\circ} \mathrm{C}$ are supposed to be related to the melting of the loose crystal of Sn. And the peaks on the exotherms (Figure $8 \mathrm{~d}$ ) at about $135^{\circ} \mathrm{C}$ correspond to the crystallization of Sn under the effect of $e_{\pi}$. Besides, the uniform dispersion of $\mathrm{Sn}$ in the matrix is speculated to be related to the interaction between graphite and $\mathrm{Sn}$. As Figure 9 shown, the $e_{\mathrm{f}}$ originally belongs to Sn participate in the graphite system along with $e_{\pi}$, which make the density of free electrons in the composites increases. Similar to the thermally conductive mech-

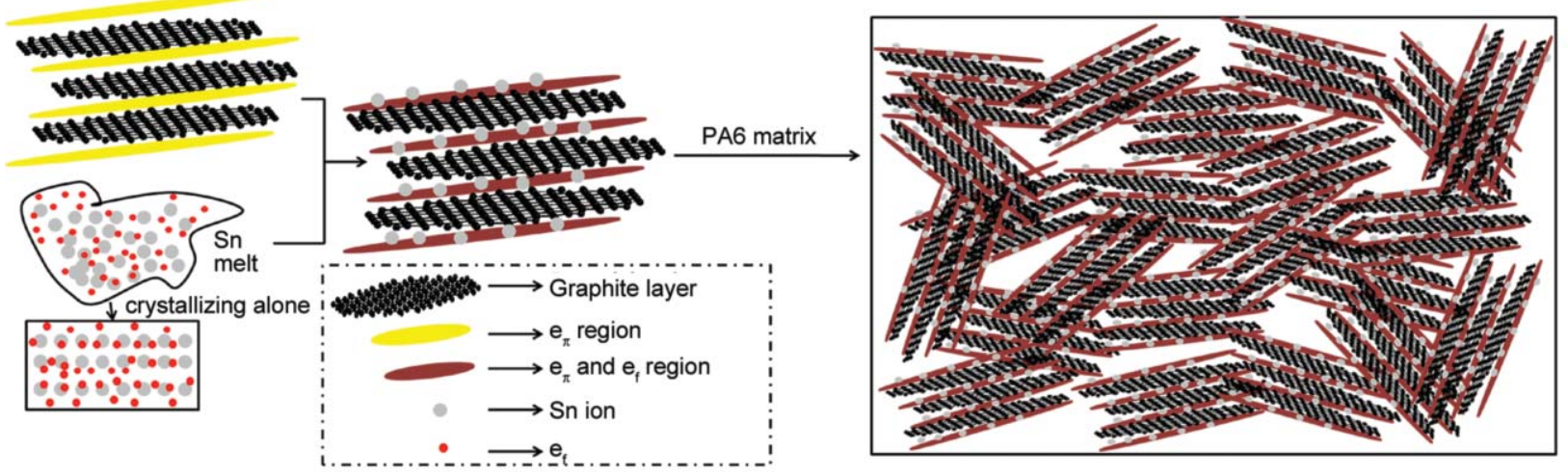

Figure 9. Sketch maps of interaction between Sn melt and graphite and filler distribution in the matrix 
anism of metal, the carrier quantity of thermal energy increases, which leads to the increase of thermal conductivity.

\subsection{Thermal degradation behavior of the composites}

The TGA curves and data of the composites are shown in Figure 10 and Table 4 respectively. For PA6/graphite composites (Figure 10a), there is only one decomposition stage in the heating process and the temperatures of weight loss at $5 \%\left(T_{5 \%}\right)$ and $10 \%$ $\left(T_{10 \%}\right)$ increase as a function of graphite content. The maximum weight loss rate $\left(R_{\max }\right)$ decreases with the increase of graphite content (Table 4). This indicates that the thermostability of the composites is enhanced, which is consistent with Kim and Jeong [51] and Zhao et al. [52]. It is believed that the graphite particles serve as the mass transfer barriers against the volatile pyrolized products in the PA6 matrix, eventually retarding thermal degradation of the composites [51, 52].

Interestingly, it could be found from Figure $10 \mathrm{~b}$ and Table 4 that with the increasing loading of Sn, both $T_{5 \%}$ and $T_{10 \%}$ of the composites initially decrease, and when the Sn content is higher than $4 \mathrm{wt} \%, T_{5 \%}$ and $T_{10 \%}$ start to rise. Compared with G50, there is an obvious decrease of the $T_{5 \%}$ and $T_{10 \%}$ when $\mathrm{Sn}$ is introduced. However, the $T_{5 \%}$ and $T_{10 \%}$ of PA6/graphite/ Sn composites are all higher than that of virgin PA6. The $R_{\max }$ of PA6/graphite/Sn composites decreases with the addition of $\mathrm{Sn}$. As noted before, graphite particles serve as the mass transfer barriers against the volatile pyrolized products in the PA6 matrix [51, 52]. When adding slight $\mathrm{Sn}$, the volatile pyrolized prod-

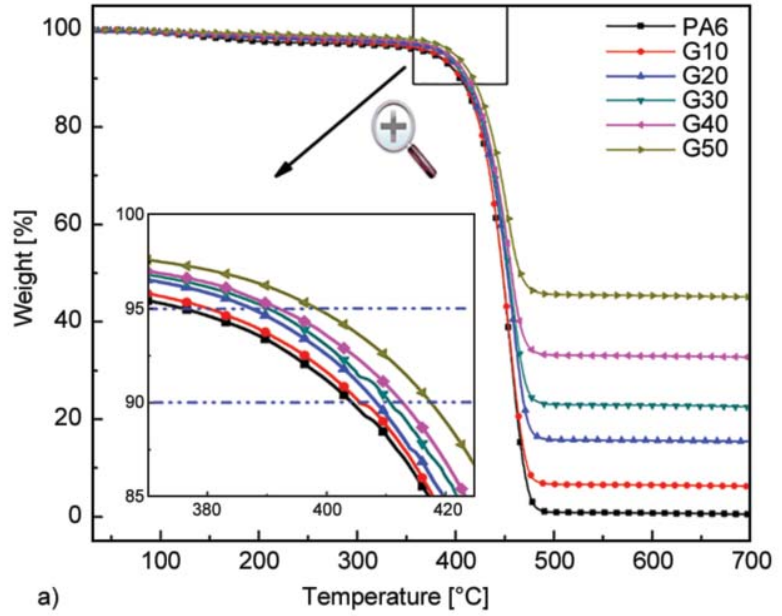

Table 4. Thermal degradation data of the composites

\begin{tabular}{|c|c|c|c|}
\hline Samples & $\begin{array}{c}\boldsymbol{T}_{\mathbf{5} \%} \\
{\left[{ }^{\circ} \mathbf{C}\right]}\end{array}$ & $\begin{array}{c}\boldsymbol{T}_{\mathbf{1 0}} \mathbf{\%} \\
{\left[{ }^{\circ} \mathbf{C}\right]}\end{array}$ & $\begin{array}{c}\boldsymbol{R}_{\max } \\
{\left[\mathbf{\%} /{ }^{\circ} \mathbf{C}\right]}\end{array}$ \\
\hline PA6 & 376.0 & 404.3 & 2.03 \\
\hline G10 & 380.2 & 405.5 & 1.94 \\
\hline G20 & 387.4 & 408.3 & 1.70 \\
\hline G30 & 390.2 & 410.6 & 1.59 \\
\hline G40 & 391.9 & 412.8 & 1.40 \\
\hline G50 & 398.3 & 417.5 & 1.18 \\
\hline GS04 & 379.9 & 407.2 & 1.00 \\
\hline GS08 & 379.9 & 407.1 & 0.87 \\
\hline GS12 & 382.1 & 407.9 & 0.86 \\
\hline GS16 & 388.0 & 411.2 & 0.77 \\
\hline GS20 & 390.2 & 414.1 & 0.64 \\
\hline
\end{tabular}

ucts would permeate the barriers of graphite easier because the low viscosity liquid metal decreases the viscosity of the system, which accounts for the initial decrease of $T_{5 \%}$ and $T_{10 \%}$. However, with the increase of Sn content, the quantity of graphite particles in the unit volume increases as discussed in the part of 3.1 (Morphology and element distribution) and the graphite's hindering effect towards the volatile increases, which explains the following increase of $T_{5 \%}$ and $T_{10 \%}$. The decrease of $R_{\max }$ of the composites is relative to the decrease of weight fraction of PA6 matrix which accounts for the major part of weight loss. In conclusion, the thermostability of the composites meliorated compared with virgin PA6.

\section{Conclusions}

A novel PA6 based material, which has a good thermal conduction was prepared by extruding and injection molding. According to this research, the distribution of single filler-Sn in PA6/Sn composites was seriously non-uniform while it had great uniformity

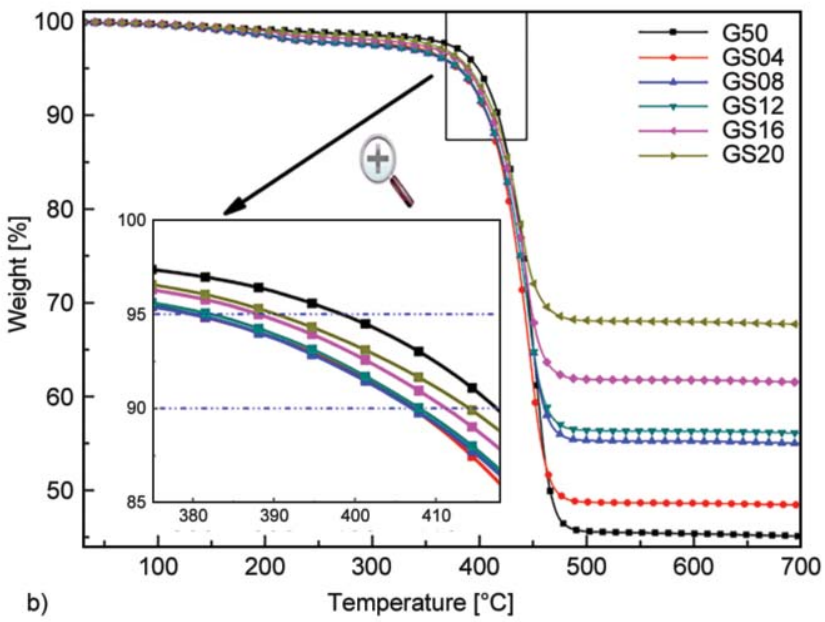

Figure 10. TGA thermograms of (a) PA6/graphite composites, and (b) PA6/graphite(50 wt\%)/Sn composites 
in PA6/graphite/Sn composites. The thermal conductivity is nearly constant when introducing $\mathrm{Sn}$ alone into PA6 matrix, while the addition of Sn could strongly boost the thermal conductivity of the PA6/graphite composites, suggesting that the introduction of graphite and further introduction of Sn have significant synergistic effect on the thermal conductivity improvement of PA6. The reason is speculated to be chemical and/or physical reaction between graphite and Sn, which would be further studied systematically in the near future. Besides, the electrical conductivity and the thermostability were also improved. The value of this work lies in the fact that apparent thermally conductive property improvement of PA6/graphite/ Sn composites has been achieved by simple and practical extruding and injection molding, which may be fruitful for the industrial-scale production of thermally conductive polymer composites.

\section{Acknowledgements}

All the authors are grateful to the Science and Technology Project of Guangdong Province 2015B010122002 for financial supports.

\section{References}

[1] Michaeli W., Pfefferkorn T. G.: Electrically conductive thermoplastic/metal hybrid materials for direct manufacturing of electronic components. Polymer Engineering and Science, 49, 1511-1524 (2009).

DOI: 10.1002/pen.21374

[2] Bormashenko E., Sutovski S., Pogreb R., Sheshnev A., Bormashenko Y., Levin M., Westfrid A.: Development of novel binary and ternary conductive composites based on polyethylene, low-melting-point metal alloy and carbon black. Journal of Thermoplastic Composite Materials, 17, 245-257 (2004). DOI: $10.1177 / 0892705704041160$

[3] Lu D., Wong C.: Isotropic conductive adhesives filled with low-melting-point alloy fillers. IEEE Transactions on Electronics Packaging Manufacturing, 23, 185-190 (2000).

DOI: $10.1109 / 6104.873246$

[4] Kim J-M., Yasuda K., Rito M., Fujimoto K.: New electrically conductive adhesives filled with low-meltingpoint alloy fillers. Materials Transactions, 45, 157-160 (2004).

[5] Mrozek R. A., Cole P. J., Mondy L. A., Rao R. R., Bieg L. F., Lenhart J. L.: Highly conductive, melt processable polymer composites based on nickel and low melting eutectic metal. Polymer, 51, 2954-2958 (2010).

DOI: $10.1016 /$ j.polymer.2010.04.067
[6] Gancarz T., Moser Z., Gąsior W., Pstruś J., Henein H.: A comparison of surface tension, viscosity, and density of $\mathrm{Sn}$ and $\mathrm{Sn}-\mathrm{Ag}$ alloys using different measurement techniques. International Journal of Thermophysics, 32, 1210-1233 (2011).

DOI: 10.1007/s10765-011-1011-1

[7] Hu M., Feng J., Ng K. M.: Thermally conductive PP/ AlN composites with a 3-D segregated structure. Composites Science and Technology, 110, 26-34 (2015). DOI: 10.1016/j.compscitech.2015.01.019

[8] He M., Qiu F., Lin Z.: Towards high-performance polymer-based thermoelectric materials. Energy and Environmental Science, 6, 1352-1361 (2013).

DOI: $10.1039 / \mathrm{c} 3 \mathrm{ee} 24193 \mathrm{a}$

[9] Chu J. R., Zhang X. H., Xu C. X.: Research and applications of thermal conducting polymer. Polymer Materials Science and Engineering, 16, 17-21 (2000).

[10] Huang X., Zhi C., Jiang P., Golberg D., Bando Y., Tanaka T.: Polyhedral oligosilsesquioxane-modified boron nitride nanotube based epoxy nanocomposites: An ideal dielectric material with high thermal conductivity. Advanced Functional Materials, 23, 1824-1831 (2013). DOI: $10.1002 /$ adfm.201201824

[11] Ishida H., Rimdusit S.: Very high thermal conductivity obtained by boron nitride-filled polybenzoxazine. Thermochimica Acta, 320, 177-186 (1998). DOI: 10.1016/S0040-6031(98)00463-8

[12] Kozako M., Okazaki Y., Hikita M., Tanaka T.: Preparation and evaluation of epoxy composite insulating materials toward high thermal conductivity. in ' $10^{\text {th }}$ IEEE International Conference on Solid Dielectrics (ICSD), Potsdam, Germany' p.4 (2010). DOI: $10.1109 /$ ICSD.2010.5568250

[13] Zhou S., Chen Y., Zou H., Liang M.: Thermally conductive composites obtained by flake graphite filling immiscible polyamide 6/polycarbonate blends. Thermochimica Acta, 566, 84-91 (2013).

DOI: $10.1016 /$ j.tca.2013.05.027

[14] Balandin A. A., Ghosh S., Bao W., Calizo I., Teweldebrhan D., Miao F., Lau C. N.: Superior thermal conductivity of single-layer graphene. Nano Letters, 8, 902907 (2008).

DOI: $10.1021 / \mathrm{n} 10731872$

[15] Kim P., Shi L., Majumdar A., McEuen P.: Thermal transport measurements of individual multiwalled nanotubes. Physical Review Letters, 87, 215502/1-215502/4 (2001).

DOI: 10.1103/PhysRevLett.87.215502

[16] Kwon S. Y., Kwon I. M., Kim Y-G., Lee S., Seo Y-S.: A large increase in the thermal conductivity of carbon nanotube/polymer composites produced by percolation phenomena. Carbon, 55, 285-290 (2013). DOI: $10.1016 /$ j.carbon.2012.12.063 
[17] Wang J., Jia H., Tang Y., Ji D., Sun Y., Gong X., Ding L.: Enhancements of the mechanical properties and thermal conductivity of carboxylated acrylonitrile butadiene rubber with the addition of graphene oxide. Journal of Materials Science, 48, 1571-1577 (2013).

DOI: 10.1007/s10853-012-6913-1

[18] Dai W., Yu J., Liu Z., Wang Y., Song Y., Lyu J., Bai H., Nishimura K., Jiang N.: Enhanced thermal conductivity and retained electrical insulation for polyimide composites with $\mathrm{SiC}$ nanowires grown on graphene hybrid fillers. Composites Part A: Applied Science and Manufacturing, 76, 73-81 (2015).

DOI: 10.1016/j.compositesa.2015.05.017

[19] Zhang W-B., Zhang Z-X., Yang J-H., Huang T., Zhang N., Zheng X-T., Wang Y., Zhou Z-W.: Largely enhanced thermal conductivity of poly(vinylidene fluoride)/carbon nanotube composites achieved by adding graphene oxide. Carbon, 90, 242-254 (2015).

DOI: $10.1016 /$ j.carbon.2015.04.040

[20] Novoselov K. S., Fal'ko V., Colombo L., Gellert P., Schwab M., Kim K.: A roadmap for graphene. Nature, 490, 192-200 (2012).

DOI: $10.1038 /$ nature 11458

[21] Zhang X., Pan Y., Cheng J., Yi X.: The influence of low-melting-point alloy on the rheological properties of a polystyrene melt. Journal of Materials Science, 35, 4573-4581 (2000).

DOI: $10.1023 / \mathrm{A}: 1004845426786$

[22] Suplicz A., Kovács J. G.: Development of thermally conductive polymer materials and their investigation. Materials Science Forum, 729, 80-84 (2012). DOI: $10.4028 /$ www.scientific.net/MSF.729.80

[23] Wierzbicki Ł., Pusz A.: Thermal conductivity of the epoxy resin filled by low melting point alloy. Archives of Materials Science and Engineering, 61, 22-29 (2013).

[24] Yuan Z. F., Mukai K., Takagi K., Ohtaka M., Huang W. L., Liu Q. S.: Surface tension and its temperature coefficient of molten tin determined with the sessile drop method at different oxygen partial pressures. Journal of Colloid and Interface Science, 254, 338-345 (2002). DOI: $10.1006 /$ jcis.2002.8589

[25] Wilkinson A. N., Clemens M. L., Harding V. M.: The effects of SEBS-g-maleic anhydride reaction on the morphology and properties of polypropylene/PA6/ SEBS ternary blends. Polymer, 45, 5239-5249 (2004). DOI: $10.1016 /$ j.polymer.2004.05.033

[26] Li L-P., Yin B., Zhou Y., Gong L., Yang M-B., Xie B-H., Chen C.: Characterization of PA6/EPDM-g-MA/HDPE ternary blends: The role of core-shell structure. Polymer, 53, 3043-3051 (2012).

DOI: $10.1016 /$ j.polymer.2012.05.003

[27] He J., Liu T., Yi Y., Tan X., Luo J., Lu A.: Internal mixing behavior and electrical conductivity of low-melting-point metals/polyethylene composites (in Chinese). Polymer Materials Science and Engineering, 28, 110 117 (2012).
[28] Ding F., Xie W. Z.: Thermally conductive composites (in Chinese). Acta Materiae Compositae Sinica, 10, 1924 (1993).

[29] Pietralla M.: High thermal conductivity of polymers: Possibility or dream? Journal of Computer-Aided Materials Design, 3, 273-280 (1996).

DOI: $10.1007 / \mathrm{BF} 01185664$

[30] Ehrenstein G. W., Riedel G., Trawiel P.: Thermal analysis of plastics: Theory and practice. Hanser, Berlin (2012).

[31] Amesöder S., Heinle C., Ehrenstein G., Schmachtenberg E.: Injection moulding of thermally conducting polymers for mechatronic applications. in 'The Polymer Processing Society $23^{\text {rd }}$ Annual Meeting, Salvador, Brasil' p.5 (2007).

[32] Ruh R., Donaldson K. Y., Hasselman D. P. H.: Thermal conductivity of boron carbide-boron nitride composites. Journal of the American Ceramic Society, 75, 28872890 (1992).

DOI: 10.1111/j.1151-2916.1992.tb05525.x

[33] Pettersson S., Mahan G. D.: Theory of the thermal boundary resistance between dissimilar lattices. Physical Review B, 42, 7386/1-7386/5 (1990).

DOI: 10.1103/PhysRevB.42.7386

[34] Kude Y., Sohda Y.: Thermal management of carbon-carbon composites by functionally graded fiber arrangement technique. in 'Functionally graded materials' (eds.: Shiota I., Miyamoto Y.) Elsevier, Oxford, 239-244 (1996). DOI: $10.1016 /$ B978-044482548-3/50040-8

[35] Bertram A., Beasley K., Torre W.: An overview of navy composite developments for thermal management. Naval Engineers Journal, 104, 276-285 (1992). DOI: $10.1111 / \mathrm{j} .1559-3584.1992 . t b 02246 . \mathrm{x}$

[36] van Beek L. K. H., van Pul B. I. C. F.: Internal field emission in carbon black-loaded natural rubber vulcanizates. Journal of Applied Polymer Science, 6, 651-655 (1962).

DOI: $\underline{10.1002 / a p p .1962 .070062408}$

[37] Ramesh C., Gowd E. B.: High-temperature X-ray diffraction studies on the crystalline transitions in the $\alpha$-and $\gamma$-forms of nylon-6. Macromolecules, 34, 3308-3313 (2001).

DOI: $10.1021 / \mathrm{ma} 0006979$

[38] Liu T., Phang I. Y., Shen L., Chow S. Y., Zhang W-D.: Morphology and mechanical properties of multiwalled carbon nanotubes reinforced nylon-6 composites. Macromolecules, 37, 7214-7222 (2004).

DOI: $10.1021 / \mathrm{ma} 049132 \mathrm{t}$

[39] Zheng W., Lu X., Wong S-C.: Electrical and mechanical properties of expanded graphite-reinforced high-density polyethylene. Journal of Applied Polymer Science, 91, 2781-2788 (2004).

DOI: $10.1002 /$ app. 13460

[40] Sorrentino L., Aurilia M., Cafiero L., Cioffi S., Iannace S.: Mechanical behavior of solid and foamed polyester/ expanded graphite nanocomposites. Journal of Cellular Plastics, 48, 355-368 (2012).

DOI: $10.1177 / 0021955 \times 12449641$ 
[41] Cerezo F. T., Preston C. M., Shanks R. A.: Morphology, thermal stability, and mechanical behavior of [poly (propylene)-grafted maleic anhydride]-layered expanded graphite oxide composites. Macromolecular Materials and Engineering, 292, 155-168 (2007). DOI: $10.1002 /$ mame.200600303

[42] Phang I. Y., Ma J., Shen L., Liu T., Zhang W-D.: Crystallization and melting behavior of multi-walled carbon nanotube-reinforced nylon-6 composites. Polymer International, 55, 71-79 (2006).

DOI: $10.1002 /$ pi. 1920

[43] Cheng H. K. F., Sahoo N. G., Pan Y., Li L., Chan S. H., Zhao J., Chen G.: Complementary effects of multiwalled carbon nanotubes and conductive carbon black on polyamide 6. Journal of Polymer Science Part B: Polymer Physics, 48, 1203-1212 (2010).

DOI: $10.1002 /$ polb. 22010

[44] Wu Q., Liu X., Berglund L. A.: An unusual crystallization behavior in polyamide $6 /$ montmorillonite nanocomposites. Macromolecular Rapid Communications, 22, 1438-1440 (2001).

DOI: $10.1002 / 1521-3927(20011101) 22: 17<1438:: A I D-$ MARC1438>3.0.CO;2-U

[45] Anderson W. P., Burdett J. K., Czech P. T.: What is the metallic bond? Journal of the American Chemical Society, 116, 8808-8809 (1994).

DOI: $10.1021 / \mathrm{ja} 00098 \mathrm{a} 050$

[46] Nittono O., Ogawa T., Gong S. K., Nagakura S.: In situ observation on melt growth process of tin crystal by means of synchrotron X-ray topography. Japanese Journal of Applied Physics, 23, L581-L583 (1984).

DOI: 10.1143/JJAP.23.L581
[47] Guerret-Piécourt C., Le Bouar Y., Lolseau A., Pascard H.: Relation between metal electronic structure and morphology of metal compounds inside carbon nanotubes. Nature, 372, 761-765 (1994).

DOI: $10.1038 / 372761 \mathrm{a} 0$

[48] Rao A. M., Eklund P., Bandow S., Thess A., Smalley R. E.: Evidence for charge transfer in doped carbon nanotube bundles from Raman scattering. Nature, 388, 257-259 (1997).

DOI: $10.1038 / 40827$

[49] Kitaura R., Imazu N., Kobayashi K., Shinohara H.: Fabrication of metal nanowires in carbon nanotubes via versatile nano-template reaction. Nano Letters, 8, 693-699 (2008).

DOI: $10.1021 / \mathrm{nl} 1073070 \mathrm{~d}$

[50] Subrahmanyam K., Manna A. K., Pati S. K., Rao C.: A study of graphene decorated with metal nanoparticles. Chemical Physics Letters, 497, 70-75 (2010).

DOI: 10.1016/j.cplett.2010.07.091

[51] Kim I-H., Jeong Y. G.: Polylactide/exfoliated graphite nanocomposites with enhanced thermal stability, mechanical modulus, and electrical conductivity. Journal of Polymer Science Part B: Polymer Physics, 48, 850-858 (2010).

DOI: $10.1002 /$ polb.21956

[52] Zhao Y. F., Xiao M., Wang S. J., Ge X. C., Meng Y. Z.: Preparation and properties of electrically conductive PPS/expanded graphite nanocomposites. Composites Science and Technology, 67, 2528-2534 (2007). DOI: $10.1016 /$ j.compscitech.2006.12.009 